\title{
ORIGINAL
}

\section{EVALUACIÓN PRE-POST DE UNA ACTIVIDAD PREVENTIVA DE LA INFECCIÓN POR VIH DIRIGIDA A LOS ADOLESCENTES DE LAS COMARCAS DEL SUR DE TARRAGONA}

Josep Rebull Fatsini (1), Montserrat Reverté Simó (2), Ismael Piñas Forcadell (3), Amat Ortí Llavería (3), Lluís González Gavilán (3) y Enric Contreras Barbeta (5)

(1) Servicio de Medicina Preventiva. Hospital de Tortosa Verge de la Cinta. Tortosa, Tarragona.

(2) ONG Àmbit Prevenció.

(3) Servicio de Medicina Interna. Hospital de Tortosa Verge de la Cinta. Tortosa, Tarragona.

(4) Servicio de Medicina Hematología. Hospital de Tortosa Verge de la Cinta. Tortosa, Tarragona.

\section{RESUMEN}

Fundamentos: La infección por el virus de la inmunodeficiencia humana (VIH) es uno de los principales problemas de salud pública que tiene nuestro país. La educación preventiva ha demostrado ser un instrumento útil en la disminución de la enfermedad. El objetivo de este trabajo es evaluar la efectividad encerna de una intervencion preventiva realizada en los Institutos de Ensenanza Secundaria (IES) de las comale sià correspondientes a la Región Sanitaria de Tortosa, orientada miento de dicho denfermedad.

Método: Se realizó un estudio de intervención antes-después, sin grupo control. Se invitó a participar a 19 centros docentes, corespondientes a los cursos de $4^{\circ}$ de Enseñanza Secundaria Obligatoria y $1^{\circ}$ de Bachillerato. La actividad consistía en un taller de 60-90 minutos de duración, adjuntando mate

Resultados: Aceptaron participar 12 centros, obteniendo 896 respuestas en el pre-test y 805 respuestas en el post-test. En el 52 $\%(10 / 19)$ de los ítems se observó un incremento, estadísticamente significativo, de las respuestas correctas en el post-test. En 4 de los 5 ítems (80\%) sobre actitudes y en 5 de los $8(62,5 \%)$ ítems sobre conocimientos generales de la infección se observó, después de la intervención, una mejora estadísticamente significativa. Sólo en 1 de los 6 ítems $(16,6 \%)$ sobre los conocimientos en preven-

Conclusiones: Las actividades preventivas en forma de talleres participativos son un buen instrumento para aumentar los conocimientos y mejorar las actitudes respecto al VIH/SIDA de lo adolescentes que participan. Al no existir tratamiento curativo para esta enfermedad, la prevención desde el ámbito educativo es relevante para frenar el aumento de transmisión del VIH.

Palabras clave: Adolescentes. VIH. Síndrome de inmunodeficiencia adquirida. Educación para la salud.

Correspondencia:

Josep Rebull Fatsini.

Servicio de Medicina Preventiva.

Hospital de Tortosa Verge de la Cinta

C/ Esplanetes, s/n. Tortosa 43500.

Tel. 977519125

Correo electrónico: prebull.htvc.ics@gencat.net

\section{ABSTRACT}

\section{Pre/post Assessment of an HIV Infection Prevention Intervention Targeted at Teenagers in Southern Tarragona}

Background: Human immuno-deficiency virus (HIV) infection is one of the leading public health problems in our country. Preventive education has shown itself to be a useful tool for curtailing this disease. The objective of this study is that of assessing the effectiveness of a preventive intervention at the Secondary Schools in the Baix Ebre and Montsià areas of the Tortosa Healthcare District aimed at reducing the risk of HIV transmission and furthering the knowledge of this disease.

Method: A pre/post intervention study was conducted with no control group. A total of 19 schools, corresponding to the fourth year of Compulsory Secondary Education and first year of «Bachillerato» studies were invited to participate. The activity consisted of a workshop 60-90 minutes in length, in conjunction with educational material. A questionnaire was used as the gauging tool.

Results: Twelve schools agreed to participate, a total of 896 answers having been gotten for the pre-test and 805 answers for the post-test. A statistically significant increase was found for $52 \%$ $(10 / 19)$ of the items regarding the correct answers on the post-test A statistically significant improvements was found in four of the five items $(80 \%)$ related to attitudes, and in five of the eight $(62.5 \%)$ items related to overall knowledge of this infection following the in tervention. A statistically significant improvement regarding prevention-related knowledge was found solely in one of the six items $(16.6 \%)$.

Conclusions: Preventive activities in the form of participational workshops are a good way of furthering the knowledge and improving the attitudes regarding HIV/AIDS of the participating teenagers. As no curative treatment exists for this disease, prevention from the educational realm is of importance for curtailing increased HIV transmission.

Key words: Adolescent. HIV. Acquired Immunodeficiency Syndrome. Health education. 


\section{INTRODUCCIÓN}

A pesar de los últimos avances farmacológicos, la infección por el virus de la inmunodeficiencia humana (VIH) es uno de los principales problemas de salud pública que tiene nuestro país. La mejor arma de que disponemos hoy en día contra el VIH/SIDA continúa siendo la educación preventiva. En un estudio publicado recientemente en Estados Unidos se estima que los esfuerzos en prevención han evitado entre los años 1978 y 2000, como mínimo, 204.000 infecciones. En cuanto a temas económicos, calcula que el gasto que genera cada caso es de un mínimo de 50.000 dólares anuales ${ }^{1}$.

En los casos de sida declarados en los últimos años se ha constatado una estabilización y descenso de la epidemia, pero España sigue siendo el país con más número de afectados de Europa. En Cataluña el número de casos notificados desde 1981 hasta el 30 de junio de 2001 ha sido de 13.902 , de los cuales 8.170 han fallecido. Las características principales de la epidemia en este entorno son: 1) Afecta sobre todo a adultos jóvenes de 25 a 39 años. 2) Hay un aumento porcentual entre mujeres heterosexuales $(39 \%$ de los casos de las mujeres notificadas en los últimos dos años) $)^{2}$.

Según una encuesta de salud en adolescentes escolarizados, realizada por la «Fundació Santiago Dexeus Font» ${ }^{3}$ en Barcelona, durante 1999, la edad de inicio de las relaciones coitales fue entre 15,7 \pm 16 años, sin diferencias entre sexos. El 18\% mantenían relaciones sexuales coitales, de los cuales un $13 \%$ utilizaba métodos anticonceptivos poco fiables o nada fiables. Por consiguiente, observamos que la prevención de la infección por VIH entre los jóvenes es todavía un instrumento fundamental para frenar la epidemia ${ }^{4}$. Uno de los ámbitos idóneos para trabajar la prevención del sida con adolescentes es la escuela, dada la cantidad de tiempo que pasan en ella y por las relaciones personales que inician con sus iguales ${ }^{5}$.
Para poder valorar la calidad de las intervenciones, diferentes estudios señalan la necesidad de que éstas se basen en un modelo teórico de cambio de conducta y que se evalúen para demostrar su efectividad ${ }^{6,7}$. Por otra parte, existen suficientes evidencias para afirmar que la lucha contra el sida no ha sido un fracaso desde el punto de vista preventivo y que es posible conseguir cambios en la conducta a largo plazo ${ }^{1,8}$.

Entre los principales pasos en educación para la salud está, en primer lugar, la adquisición de elementos cognitivos, aunque ésta no sea indicativa de un cambio de conducta. El segundo es la percepción, a través de la cual se otorga cierto valor a las consecuencias de la acción. Uno de los modelos teóricos más usados en promoción de la salud es el Modelo de Creencias de Salud (MCS) ${ }^{9}$. Este modelo se basa en tres premisas:

- La creencia o percepción de que un determinado problema es importante o suficientemente grave para tenerlo en consideración.

- La creencia o percepción de que uno es vulnerable respecto al problema.

- La creencia o percepción de que la acción a realizar producirá un beneficio con un coste aceptable.

De acuerdo con el MCS, la concurrencia simultánea de estos tres factores favorece la adopción de determinados patrones de conducta $^{10}$.

Los resultados de las líneas de trabajo desarrollados actualmente apuestan por una alternativa a los modelos jerárquicos de información basados en expertos ${ }^{11,12}$. Según éstas, las intervenciones deberían ajustarse a las características de cada grupo y los mensajes tendrían que ser relevantes para la vida cotidiana de las personas, reemplazando el vocabulario médico por uno de fácil manejo y más explícito. 
El objetivo del presente trabajo es evaluar la efectividad de la intervención preventiva, para lo cual es necesario detectar y cuantificar cambios en las actitudes y conocimientos sobre prevención y transmisión de la infección por VIH en los adolescentes participantes en el estudio.

\section{SUJETOS Y MÉTODO}

Se realizó un estudio de intervención antes-después sin grupo control. A través de un cuestionario estructurado se realizó un «pre-test», con el fin de analizar los conocimientos y actitudes sobre el VIH de los adolescentes antes de las intervenciones programadas en forma de talleres, para que después de esta intervención se volviese a pasar un cuestionario «post-test» y comparar, de este modo, los resultados en los dos momentos.

\section{Ámbito, población y período de estudio}

El ámbito de estudio son las comarcas del Montsià y Baix Ebre que forman parte de la Región Sanitaria de las Tierras del Ebro en la provincia de Tarragona, con una población adscrita de 125.000 habitantes.

La población objeto de estudio estaba formada por adolescentes que en el momento de la investigación se encontraban en $4^{\circ}$ de ESO y $1^{\circ}$ de Bachillerato, en edades comprendidas entre 14 y 17 años, en los institutos de estas comarcas y durante el año académico de 2000-01. Entre las 2 comarcas existen 19 centros de educación secundaria. El total de alumnos matriculados durante ese curso escolar en cuarto de Educación Secundaria Obligatoria fue de 1.582 .

El estudio se incluyó dentro de un proyecto de prevención de la transmisión del VIH dirigido a adolescentes que se inició durante el curso escolar 95-96, al cual se han ido adhiriendo progresivamente los centros de enseñanza de la zona. El proyecto pretende llegar al máximo número posible de adoles- centes para incrementar la información sobre la infección, los mecanismos de transmisión y las medidas de prevención del VIH/SIDA entre este colectivo y, simultáneamente, promover el diálogo entre los jóvenes sobre dicha enfermedad.

La parte del cuestionario correspondiente al «pre-test» se pasó inmediatamente antes de la realización de cada taller y la parte correspondiente al «pos-test», 6 meses después de la intervención, a lo largo del curso 2000-01. El «post-test» fue enviado por correo a cada uno de los centros, adjuntando una carta explicativa sobre el objetivo del estudio, la importancia de su participación y las instrucciones para pasar el pos-test a los alumnos. La introducción de los datos obtenidos y el análisis de los mismos se realizó de septiembre a diciembre de 2001.

\section{Estructura del cuestionario}

El cuestionario se escogió a partir de la búsqueda bibliográfica previa sobre estudios parecidos, diseñados para el mismo tipo de población. En Algemesí se había realizado una intervención similar con el nombre de Aula SIDA y el cuestionario utilizado, previamente validado, se adecuaba a nuestro tipo de población ${ }^{13}$. Se realizó una prueba piloto $^{14}$ del mismo en dos de los talleres para poder valorar la comprensión de las preguntas y finalmente, se decidió conservar todas las preguntas del cuestionario original.

La encuesta fue individual, anónima y auto administrada, traduciéndose previamente al catalán por ser el idioma predominante entre los alumnos (anexo 1).

Al inicio del cuestionario, los alumnos tenían que rellenar sus datos básicos que incluían el nombre del centro escolar, la localidad, el curso, el sexo y la edad. Seguidamente venían 19 preguntas cerradas con 3 posibilidades (verdadero, falso, no lo sé). De las 19 preguntas, 14 hacían referencia a conceptos de trans- 
misión y prevención de la infección por VIH y 5 se referían a actitudes sobre escenarios hipotéticos planteados alrededor de su vida social y de su relación con los otros.

\section{Descripción de la intervención}

Los talleres se realizaron siguiendo una metodología de trabajo que permitía abrir espacios de diálogo entre los jóvenes durante el transcurso de la sesión ${ }^{15}$. Se realizaban en sus propias aulas, en horario escolar, con una duración de 60 a 90 minutos y en una sola sesión. Se basaban en el MCS, en función de las preguntas que realizaban los alumnos o del debate que se plantease al finalizar la exposición informativa por parte de los profesionales. Las actividades se realizaban con soporte audiovisual ${ }^{16}$ en forma de transparencias, folletos informativos y también se sumaron juegos didácticos participativos.

Guión del taller: a) Introducción: El conductor del taller introducía el tema y proporcionaba información básica sobre la infección. b) Discusión: Se planteaban cuestiones básicas que se discutían en grupos reducidos y posteriormente se ponían en común las diferentes opiniones. c) Información: A partir de las conclusiones de los diferentes gru- pos, el conductor del taller clarificaba la información. d) Juego de rol: Mientras se estaban realizando los grupos de discusión, se proponía a 2-4 alumnos que esbozasen un diálogo que representara, de la forma más real posible, alguna situación en que podrían encontrarse referente a la prevención o transmisión del VIH. Al acabar las exposiciones de los grupos y de la intervención del tallerista se interpretaban los diálogos ante el resto del grupo. e) Conclusiones: La parte final se dedicaba a un debate conjunto con el objetivo de extraer las conclusiones de la sesión.

\section{Análisis de datos}

Las variables continuas fueron expresadas como media y desviación estándar. Las variables del cuestionario fueron tratadas como variables cualitativas y fueron expresadas en frecuencias absolutas y porcentajes; para su comparación se utilizó el test del $\chi^{2}$. Se consideró como valor de significación estadística una $\mathrm{p}<0,05$.

\section{RESULTADOS}

De un total de 19 centros docentes existentes en el ámbito de estudio, participaron

Tabla 1

Características sociodemográficas de la población estudiada

\begin{tabular}{|lll|}
\hline Variables & $\begin{array}{r}\text { Pre-test } \\
(\mathbf{N}=\mathbf{8 9 6})\end{array}$ & $\begin{array}{r}\text { Post-test } \\
(\mathbf{N}=\mathbf{8 0 5})\end{array}$ \\
\hline $\begin{array}{l}\text { Sexo } \\
\text { Hombre } \\
\text { Mujer }\end{array}$ & $455(50,8 \%)$ & $394(48,9 \%)$ \\
& 441 & 411 \\
Edad & & \\
Media & 15,60 & 15,92 \\
DS & 0,70 & 0,79 \\
Nivel académico & & \\
$4^{\circ}$ ESO & $729(81,3 \%)$ & $711(88,3 \%)$ \\
$1^{\circ}$ Bachillerato & 168 & 94 \\
Comarcas & & $242(30 \%$ \\
Baix Ebre & $238(26,6 \%)$ & 562 \\
Montsia & 658 & \\
\hline
\end{tabular}


$12(63 \%)$. De 1.582 alumnos matriculados en $4^{\circ}$ de ESO realizaron el taller y respondieron en el pre-test $729(46,1 \%)$ y 711 en el post-test ( 8 centros). Además se incluyeron 8 talleres realizados a alumnos de primero de bachillerato (168). La muestra total de alumnos que realizaron el pre-test fue de 896 y el pos-test fue de 805 . Las características del alumnado se describen en la tabla 1.
Los resultados obtenidos antes y después de la intervención educativa se exponen en la tabla 2. Se han diferenciado tres conceptos: cambios en las actitudes, cambios en los conocimientos generales sobre la enfermedad y conocimientos sobre prevención de la enfermedad.

Respecto a las actitudes, sobre 5 ítems, en $4(80 \%)$ se ha observado una mejora estadís-

Tabla 2

Porcentaje de alumnos que responden correctamente cada pregunta en el pre y post-test

\begin{tabular}{|c|c|c|c|c|c|}
\hline ITEMS & $\begin{array}{c}\mathrm{N}^{\circ} \text { correctas } \\
(\%)\end{array}$ & $\begin{array}{l}N^{\circ} \text { alumnos } \\
(\%)\end{array}$ & Valor p & $\begin{array}{l}\% \text { cambio } \\
\text { respuestas } \\
\text { correctas }\end{array}$ & $\begin{array}{c}\text { valoración de la } \\
\text { efectividad }\end{array}$ \\
\hline \multicolumn{6}{|c|}{ ACTITUDES } \\
\hline $\begin{array}{l}\text { El SIDA es cosa de drogadictos y } \\
\text { homosexuales. }\end{array}$ & $\begin{array}{l}\text { Pre } \\
\text { Post }\end{array}$ & $\begin{array}{l}95,0 \% \\
91,6 \%\end{array}$ & 0.01 & 3.7 & Empeora \\
\hline $\begin{array}{l}\text { A la persona portadora del virus del SIDA se le } \\
\text { nota enseguida. }\end{array}$ & $\begin{array}{l}\text { Pre } \\
\text { Post }\end{array}$ & $\begin{array}{l}83,3 \% \\
87,1 \% \\
\end{array}$ & 0.00 & 4.3 & Mejoría \\
\hline $\begin{array}{l}\text { Tendría inconveniente en estar en clase con una } \\
\text { compañera/o con SIDA. }\end{array}$ & $\begin{array}{l}\text { Pre } \\
\text { Post }\end{array}$ & $\begin{array}{l}67,7 \% \\
81,1 \%\end{array}$ & 0.00 & 19.7 & Mejoría \\
\hline $\begin{array}{l}\text { Tendría miedo de contagiarme si viviese con un } \\
\text { familiar/persona enfermo de SIDA. }\end{array}$ & $\begin{array}{l}\text { Pre } \\
\text { Post }\end{array}$ & $\begin{array}{l}31,9 \% \\
37,8 \% \\
\end{array}$ & 0.03 & 18.49 & Mejoría \\
\hline $\begin{array}{l}\text { Si entre mi grupo un compañero tuviese el } \\
\text { SIDA, cambiaría mi relación por este motivo. }\end{array}$ & $\begin{array}{l}\text { Pre } \\
\text { Post }\end{array}$ & $\begin{array}{l}70,2 \% \\
82,3 \%\end{array}$ & 0.00 & 17.2 & Mejoría \\
\hline \multicolumn{6}{|c|}{ CONOCIMIENTOS SOBRE LA INFECCIÓN } \\
\hline $\begin{array}{l}\text { Una persona portadora del virus del SIDA puede } \\
\text { tener un aspecto totalmente sano. }\end{array}$ & $\begin{array}{c}\text { Pre } \\
\text { Post }\end{array}$ & $\begin{array}{l}83,5 \% \\
89,7 \%\end{array}$ & 0.00 & 6.9 & Mejoría \\
\hline $\begin{array}{l}\text { El virus del SIDA se puede transmitir a través } \\
\text { del aire (tos, etc.). }\end{array}$ & $\begin{array}{l}\text { Pre } \\
\text { Post }\end{array}$ & $\begin{array}{l}90,0 \% \\
92,5 \%\end{array}$ & 0.14 & 2.7 & Sin cambios \\
\hline $\begin{array}{l}\text { Desde hace un año hay una medicina que cura el } \\
\text { SIDA. }\end{array}$ & $\begin{array}{l}\text { Pre } \\
\text { Post }\end{array}$ & $\begin{array}{l}61,4 \% \\
69,6 \%\end{array}$ & 0.00 & 11.7 & Mejoría \\
\hline $\begin{array}{l}\text { Existe alguna forma de saber si una persona } \\
\text { tiene el SIDA. }\end{array}$ & $\begin{array}{l}\text { Pre } \\
\text { Post }\end{array}$ & $\begin{array}{l}94,4 \% \\
93,7 \%\end{array}$ & 0.02 & 0.7 & empeora \\
\hline $\begin{array}{l}\text { Por las relaciones sexuales se puede transmitir el } \\
\text { virus del SIDA. }\end{array}$ & $\begin{array}{l}\text { Pre } \\
\text { Post }\end{array}$ & $\begin{array}{l}98,3 \% \\
96,9 \% \\
\end{array}$ & 0.08 & 1.4 & Sin cambios \\
\hline $\begin{array}{l}\text { Los insectos pueden transmitir el virus del } \\
\text { SIDA. }\end{array}$ & $\begin{array}{l}\text { Pre } \\
\text { Post }\end{array}$ & $\begin{array}{l}29,7 \% \\
36,3 \% \\
\end{array}$ & 0.00 & 18.2 & Mejoría \\
\hline $\begin{array}{l}\text { Haciendo deporte con personas portadoras del } \\
\text { virus del SIDA o usando su ropa o toallas, hay } \\
\text { riesgo de coger la enfermedad. }\end{array}$ & $\begin{array}{l}\text { Pre } \\
\text { Post }\end{array}$ & $\begin{array}{l}72,7 \% \\
74,9 \%\end{array}$ & 0.12 & 2.9 & Sin cambios \\
\hline $\begin{array}{l}\text { Si a una persona se le hace una transfusión de } \\
\text { sangre en nuestro país, hay riesgo de coger la } \\
\text { enfermedad. }\end{array}$ & $\begin{array}{l}\text { Pre } \\
\text { Post }\end{array}$ & $\begin{array}{l}40,8 \% \\
51,6 \%\end{array}$ & 0.00 & 20.9 & Mejoria \\
\hline \multicolumn{6}{|c|}{ CONOCIMIENTOS SOBRE LA PREVENCIÓN DE LA INFECCIÓN } \\
\hline $\begin{array}{l}\text { Es útil para evitar contagios utilizar el } \\
\text { preservativo cuando sea necesario. }\end{array}$ & $\begin{array}{l}\text { Pre } \\
\text { Post }\end{array}$ & $\begin{array}{l}97,3 \% \\
96,8 \%\end{array}$ & 0.74 & 0.5 & Sin cambios \\
\hline Es útil para evitar contagios no dar sangre. & $\begin{array}{l}\text { Pre } \\
\text { Post }\end{array}$ & $\begin{array}{l}67,0 \% \\
64,1 \% \\
\end{array}$ & 0.46 & 4.5 & Sin cambios \\
\hline $\begin{array}{l}\text { Es útil para evitar contagios bañarse con agua } \\
\text { muy caliente. }\end{array}$ & $\begin{array}{l}\text { Pre } \\
\text { Post }\end{array}$ & $\begin{array}{l}71,5 \% \\
62,2 \% \\
\end{array}$ & 0.00 & 14.9 & Empeora \\
\hline $\begin{array}{l}\text { Es útil para evitar contagios evitar la droga y } \\
\text { compartir agujas o jeringas. }\end{array}$ & $\begin{array}{l}\text { Pre } \\
\text { Post }\end{array}$ & $\begin{array}{l}92,0 \% \\
94,3 \% \\
\end{array}$ & 0.09 & 2.4 & Sin cambios \\
\hline $\begin{array}{l}\text { Es útil para evitar contagios no mantener } \\
\text { relaciones sexuales. }\end{array}$ & $\begin{array}{l}\text { Pre } \\
\text { Post }\end{array}$ & $\begin{array}{l}20,6 \% \\
16,0 \% \\
\end{array}$ & 0.00 & 28.75 & Empeora \\
\hline Es útil para evitar contagios hacer ejercicio. & $\begin{array}{l}\text { Pre } \\
\text { Post }\end{array}$ & $\begin{array}{l}65,5 \% \\
68,7 \%\end{array}$ & 0.00 & 4.2 & Mejoría \\
\hline
\end{tabular}


Figura 1

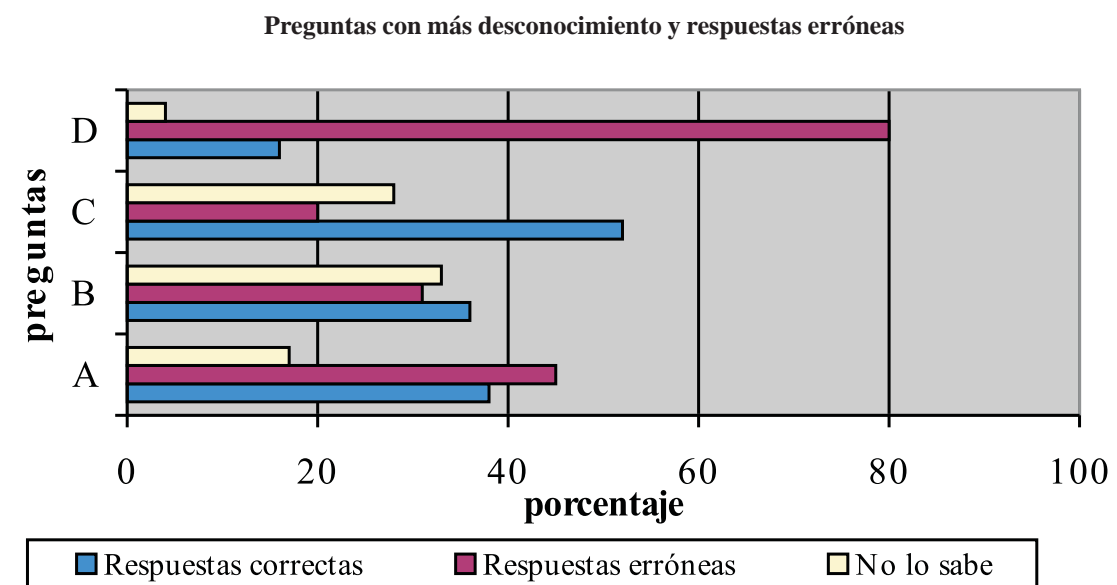

A. «Tendría miedo de contagiarme si viviese con un familiar/persona enfermo de sida».

B. «Los insectos pueden transmitir el virus del sida».

C. «Si a una persona se le hace una transfusión de sangre en nuestro país, hay riesgo de coger la enfermedad».

D. «Es útil para evitar contagios no mantener relaciones sexuales».

ticamente significativa, después de la intervención educativa, y en un ítem se ha constatado un empeoramiento. Lo que más destaca en este apartado es el bajo porcentaje de aciertos en la pregunta ¿tendría miedo de contagiarme si viviese con un familiar/persona enferma del SIDA? Un $32 \%$ respondieron correctamente en el pre-test y un $38 \%$ en el post, destacando el incremento substancial en el post-test de un 18'5\% más de respuestas correctas $(\mathrm{p}=0,03)$.

En cuanto a los conocimientos generales sobre la enfermedad, de 8 ítems mejoraron significativamente un 50\%, 12,5\% empeoraron y en el $37,5 \%$ no se obtuvieron cambios. Destaca el incremento de respuestas acertadas en el pos-test en el ítem «los insectos pueden transmitir el virus del SIDA», con un incremento del $18 \%(\mathrm{p}<0,001)$ y en el ítem »en una transfusión de sangre en nuestro país hay riesgo de contraer la enferme$d a d »$ se constata un incremento de respuestas positivas de un $20 \%$ ( $p<0,001)$. En los dos casos se obtuvo un incremento significativo en las preguntas que presentaban niveles bajos de respuestas correctas en el pre-test.
En el apartado de conocimientos sobre la prevención de la enfermedad es el área donde menos beneficios hemos visto, sólo 1 de los ítem obtuvo mejoría $(16,6 \%)$ y en 2 ítems se constató un empeoramiento significativo $33,3 \%$. Destaca el ítem «es útil para evitar contagios no mantener relaciones sexuales» donde solo un $16 \%$ en el post-test respondió correctamente ( $20 \%$ en el pre-test).

La pregunta donde había más porcentaje de desconocimiento en el post-test fue, con un 33\% «los mosquitos pueden transmitir el virus del SIDA». En la figura 1 se exponen las preguntas con porcentaje más bajo de aciertos y desconocimiento más alto.

\section{DISCUSIÓN}

Los resultados de nuestro trabajo demuestran que la intervención preventiva sobre educación sanitaria en forma de talleres puede ser un instrumento útil para aumentar conocimientos y mejorar actitudes sobre la infección por VIH. Este resultado concuerda con los de otros estudios realizados en pobla- 
ciones similares ${ }^{13,17}$. Existe la evidencia de que en un $56 \%$ de las intervenciones estudiadas se consigue un incremento de los conocimientos y casi todos mejoran las actitudes ${ }^{18}$. En nuestro caso los mayores incrementos se han producido en las preguntas que presentaban un porcentaje de aciertos más bajo.

Entre las limitaciones a destacar en el presente trabajo se encuentra la del diseño prepost, ya que al no tener un grupo control resulta difícil determinar si los resultados pueden ser debidos a alguna otra intervención o a la adquisición de información por otras fuentes. En nuestro caso entre la realización del taller y el pos-test no se realizó ninguna otra actividad sobre el VIH/sida en el ámbito escolar.

Entre los resultados más evidentes del presente trabajo destaca una falta de conocimientos en algunos aspectos, como la transmisión por picaduras de insectos y por donación de sangre, que también se constata en otros trabajos como el realizado en California sobre 3.034 adultos heterosexuales ${ }^{19} \mathrm{o}$ el de Algemesí en la Comunidad Valenciana13 que obtuvieron un $31,9 \%$ y el $20 \%$. Por otra parte, destaca el gran número de aciertos en aspectos de prevención como el uso del preservativo o el de evitar compartir jeringuillas, donde el nivel de respuestas correctas antes de la intervención es superior al $90 \%$, lo cual también explica que en cuanto a prevención es donde se ha obtenido menos mejora. Las áreas con más posibilidad de mejora continúan siendo algunos aspectos de la transmisión no relacionadas con las actividades sexuales o de drogadicción, así como las relacionadas con las actitudes, como por ejemplo «tendría miedo de contagiarme si viviese con un familiar/persona enfermo de SIDA».

Se decidió dejar todas las preguntas del cuestionario original, si bien a posteriori hemos podido constatar que alguna pregunta no refleja exactamente el grado de conocimientos que se tienen sobre el tema. Concre- tamente, la pregunta «es útil para evitar contagios no mantener relaciones sexuales» con un bajo porcentaje de respuestas acertadas, ha podido producir confusión ya que no se especifica qué tipo de relaciones sexuales (masturbación, penetración, etc.) y por otra parte la prevención es uno de los puntos donde se dedica más tiempo en los talleres y se especifican las diferentes prácticas de riesgo. También ha podido influir en las respuestas un componente subjetivo de utilización de preservativo que no especificaba la pregunta.

Otras posibles limitaciones del estudio pueden ser el tiempo de respuesta al cuestionario (no más de 15 minutos), lo cual ha podido condicionar que las preguntas que requieran un cierto tiempo de reflexión, como las formuladas negativamente, fuesen contestadas erróneamente, pero por otra parte aportaba las ventajas de un cuestionario auto administrado que evita distorsiones del entrevistador, y el hecho de ser anónimo favorece una elevada participación. Finalmente la menor respuesta en el post-test que en el pre-test, que ha venido condicionada por el diseño del estudio al dejar de 6 meses entre la actividad y la evaluación.

Haciendo referencia a la metodología de los talleres, las acciones informativas/ formativas se deben basar en tres demandas de los jóvenes: 1. Coherencia (correlación entre temática e institución). 2. Constancia (mayor frecuencia de actividades y periodicidad predeterminada de las mismas). 3 . Extensión (cobertura masiva e inclusión de todas las escuelas y colegios $)^{20}$. De estos tres aspectos, el único que no cumple nuestra actividad es el segundo, ya que se trata de intervenciones puntuales dentro del curso escolar. El trabajo preventivo en forma de taller de una hora muestra tener efecto entre los jóvenes, aunque resulta insuficiente si no va acompañado de otros aspectos que apoyen y refuercen su proceso de maduración tanto desde la familia, como desde la escuela, como desde los profesionales de la salud, 
con la finalidad de que llegado el momento de la toma de decisiones responsables, puedan tener recursos personales para ello. Es necesario que las escuelas adquieran un mayor compromiso mediante acciones más sostenidas, que permitan abordar la prevención frente al VIH desde diferentes ángulos, como por ejemplo desde la sexualidad, desde el entorno, desde la asertividad, etc. Una reciente metodología de trabajo es a través de grupos de iguales, para la cual se trabaja conjuntamente con los jóvenes, procurándoles una formación en el tema a tratar con la finalidad de que difundan esa información a personas de su mismo grupo social, en cuanto a edad, a nivel de estudios o a situación social, en su propio entorno natural. Esta estrategia ha mostrado ser eficaz en el fomento de la adopción de comportamientos preventivos con respecto al VIH/SIDA ${ }^{21}$. Por otra parte resulta básico, frente a la prevención del VIH/SIDA, facilitar el acceso a preservativos y a los centros de salud sexual confidenciales.

En cuanto a la extensión de la actividad preventiva, participaron 12 centros de 19 (63\%). Creemos que es un buen porcentaje. Entre los centros que no participaron, 2 fue porque ya habían realizado alguna actividad preventiva por parte del profesorado, y el resto por problemas de horario y calendario escolar, de todas formas las características de los centros y de los alumnos que no participaron en el estudio son similares a la de los que sí lo hicieron.

La realidad actual muestra que ante la ausencia de un tratamiento curativo, el trabajo sobre el cambio de comportamiento es la única arma de que disponemos en la lucha contra el VIH/SIDA, y esto siempre resulta difícil, hasta en las mejores condiciones ${ }^{20}$. Además, la información de forma aislada no resulta eficaz si no se valora desde una perspectiva sobre su gran potencial como dispositivo de apertura a preguntas que el joven no se plantea ${ }^{18}$. Por esta razón necesitamos incorporar intervenciones que incluyan el máximo de recursos disponibles para conseguir los objetivos, y el $\mathrm{MCS}^{10}$ supone una buena estrategia que se adapta a las características de la población diana, aunque se le acusa de plantear relaciones de causalidad.

En el futuro se prevé un conjunto de cambios entre los que destaca un incremento de la infección del VIH entre los jóvenes de las clases media y medias-bajas y también un incremento importante de las enfermedades de transmisión sexual. Este conjunto de cambios exigirá abordar desde ahora mismo una importante tarea de información, formación y educación entre los jóvenes ${ }^{22}$.

\section{AGRADECIMIENTOS}

Agradecemos la participación en el estudio a todos los centros educativos que lo integran, tanto al profesorado como a los alumnos.

Este estudio se ha realizado en el marco de un proyecto preventivo dirigido a adolescentes, el cual está subvencionado por el «Programa per a la prevenció i l'assistència de la sida» del Departament de Sanitat de la Generalitat de Catalunya, sin cuyo apoyo no se hubiera podido llevar a término

\section{BIBLIOGRAFÍA}

1. Holtgrave D. Estimating the effectiveness and efficiency of US HIV prevention efforts using scenario and cost-effectiveness analysis. AIDS 2002; $16: 2347-2349$.

2. Vigilància epidemiològica de la SIDA a Catalunya. Situació fins al 30 de juny del 2001. Departament de Sanitat i Seguretat Social. Butlletí Epidemiològic de Catalunya núm10, 2001.

3. Surís JC, Parera N. Enquesta de salut als adolescents escolaritzats de la ciutat de Barcelona 1999. Barcelona: Fundació Santiago Dexeus Font, 2000.

4. Karungari Kirago Ph.D. Los jóvenes y el VIH/SIDA ¿Podemos evitar una catástrofe?. Population reports 2001; XXIX:1-36. 
5. Svenson G, et al. Annotated bibliography about youth AIDS peer education in Europe. European Commission: 1998.

6. Fernández Costa S, Juárez Martínez O, Díez David, E. Prevención del SIDA en la escuela secundaria: recuperación y valoración de programas. Rev Esp Salud Pública 1999; 73:687-696.

7. Oakaley A, Fullerton D, Holland, J. Behavioural interventions for VIH/AIDS prevention. AIDS 1995; 9:479-486.

8. UNAIDS. Innovative approaches to HIV prevention. UNAIDS Geneva, 2000.

9. Becker MH. The health belief model and personal health behavior. Health Education Monograph 1974;2.(número completo)

10. Soto Mas F, Lacoste Marín J, Papenfuss R, Gutiérrez León A. El modelo de creencias de salud. Un enfoque teórico para la prevención del SIDA. Rev Esp Salud Pública 1997; 71:335-341.

11. López Sánchez F. Educación sexual de adolescentes y jóvenes. Ed. Siglo XXI. Madrid 1995

12. UNICEF. Young people in changing societies. Regional monitoring repport, $\mathrm{n}^{\circ} 7$ Summary. 2000.

13. Fernández García C, Molina Quilis R, Ramírez Sampedro C, Pérez Pérez E, y col. Cambios en las actitudes y conocimientos de los adolescentes sobre la infección por VIH tras la intervención escolar Aula SIDA. Rev Esp Salud Pública 2000; 74:163-176.

14. Escribá, V. Diseño de cuestionarios. En: Rebagliato M, Ruiz I, Arranz M, editores. Metodología de investigación en epidemiología. Ed. Díaz de Santos; 1996. p. 113-134.
15. CDC. Guidelines for effective schooll health Education to Prevent the Spread of AIDS. MMWR 37; $1-14$.

16. Fundació La Caixa: Sida: saber ajuda. Programa educatiu multidisciplinar per al coneixement i la prevenció de la SIDA. Barcelona: Fundació La Caixa. 1994.

17. Castilla J, Barrio G, de la Fuente L, and Belza MG. Sexual behavior and condom use in the general population in Spain, 1996. Aids Care 1998; 110:66776.

18. Juárez O, Díez E. Prevención del SIDA en adolescentes escolarizados: una revisión sistemática de la efectividad de las intervenciones. Gac. Sanit 1999; 13:150-62.

19. Bastani R, Erickson PA, Marcus AC, Maxwell AE, Capell FJ, Freemann H, I Cols. Aids-related attitudes and risk behaviors. A survey of a random sample of California heterosexuals. Prev Med 1996; 25:105-17.

20. Portero López P, Cirne Lima R, Mathieu G. La intervención en adolescentes y jóvenes en la prevención y promoción de la salud. Rev. Esp. Salud Pública 2002; 76:577-584.

21. ONUSIDA. Educación inter pares y VIH/SIDA: Conceptos, usos y problemas. ONUSIDA/99.46S (Versión española, setiembre de 2000).

22. Conde Gutiérrez F. Escenarios de futuro del VIHSIDA: de la enfermedad «acontecimiento» a la cronicidad difusa. Del estigma moral a las zonas más centrales de la vulnerabilidad social. Rev. Esp. Salud Pública 1997; 71:1-7. 


\section{Anexo 1}

Cuestionario individual anónimo

Centro

Localidad

Curso: ESO, Ciclos formativos, BUP, Otros

Hombre

Mujer

Edad

\section{A las siguientes propuestas conteste verdadero, falso, o no lo sé}

A.- Una persona portadora del virus del SIDA puede tener un aspecto totalmente sano.

B.- El SIDA es cosa de drogadictos y homosexuales.

C.-A la persona portadora del virus del SIDA se le nota enseguida.

D.- El virus del SIDA se puede transmitir a través del aire (tos, etc.).

E.- Desde hace un año hay una medicina que cura el SIDA.

F.- Existe alguna forma de saber si una persona tiene el SIDA.

G.- Por las relaciones sexuales se puede transmitir el virus del SIDA.

H.- Los insectos pueden transmitir el virus del SIDA.

I.- Haciendo deporte con personas portadoras del virus del SIDA o usando su ropa o toallas, hay riesgo de coger la enfermedad.

J.- Si a una persona se le hace una transfusión de sangre en nuestro país, hay riesgo de coger la enfermedad

K.- Tendría inconveniente en estar en clase con una compañera/o con SIDA.

L.- Si entre mi grupo, un compañero tuviese el SIDA, cambiaría mi relación por este motivo.

M.- Tendría miedo de contagiarme si viviese con un familiar/persona enfermo de SIDA

\section{Para evitar contagios Es útil:}

N1.- Utilizar el preservativo cuando haga falta.

N2.- No dar sangre.

N3.- Bañarse con agua muy caliente.

N4.- Evitar la droga y el uso compartido de agujas o jeringas

N5.- No mantener relaciones sexuales.

N6.- Hacer ejercicio. 